\title{
Determination of Heavy Metal Ions Based on Quenching of the Rare Earth Luminescence
}

\author{
Tsuyoshi ARAKAWA, * Masami AKAMINE, and Akiko MURAKI
}

\begin{abstract}
Department of Biological and Environmental Chemistry, Kyushu School of Engineering, Kinki University (Kayanomori 11-6, Iizuka, Fukuoka 820-8555, Japan)
\end{abstract}

Received November 18, 2002 ; Accepted February 17, 2003

\begin{abstract}
The determination of heavy metal ions based on quenching of the rare earth luminescence was investigated. A few heavy metal ions efficiently quenched the luminescence of $\mathrm{Ce}^{3+}$ in polymerized cellulose films which were obtained by $\mathrm{Na}-\mathrm{CMC}$ (sodium carboxymethyl cellulose) solution and $\mathrm{CeCl}_{3}$ solution or the mixed solution of $\mathrm{CeCl}_{3}$ and a heavy metal chloride. Also, the decay time of $\mathrm{Ce}^{3+}$ ions $(\tau)$ in $\mathrm{Ce}^{3+}-\mathrm{Cu}^{+}, \mathrm{Ce}^{3+}-\mathrm{Cu}^{2+}, \mathrm{Ce}^{3+}-\mathrm{Zn}^{2+}$ and $\mathrm{Ce}^{3+}-\mathrm{Pb}^{2+}$ system was shorter than that of only $\mathrm{Ce}^{3+}$ system $\left(\tau_{0}\right)$. The linear relationship between the concentration of $\mathrm{Cu}^{2+}, \mathrm{Zn}^{2+}$ or $\mathrm{Pb}^{2+}$ ions and $\tau_{0} / \tau$ reflected the dynamic quenching, as predicted by the Stern-Volmer equation.
\end{abstract}

Key Words : Heavy Metal Ions, Rare Earth, Luminescence, Decay Time

\section{Introduction}

Many rare earth complexes attract the interest as fluorescent probes in detection applications. The structural optimization of the rare earth complexes enhanced the availability in the molecular recognition and chirality sensing of biological substances. "2 It was reported that terbium chelate was used as a label in fluorescent immunoassays. ${ }^{3)}$ The polymers including the rare earth complex were synthesized, and the fluorescence was examined with the aim of the application to laser materials, etc.. ${ }^{4}$ The hydrolysis product of the nerve agent Soman in water could be measured by the luminescence of $\mathrm{Eu}^{3+}$-polymer complexes containing methyl-3, 5dimethylbenzoate ligand. ${ }^{5}$ ) We reported that the copper ions $\left(\mathrm{Cu}+\right.$ or $\left.\mathrm{Cu}^{2+}\right)$ could be detected using the fluorescence property of rare earth element $\left(\mathrm{Eu}^{3+}\right)$ in polymerized cellulose films, which was prepared from sodium carboxymethyl cellulose (Na-CMC) solution and the mixed solution of heavy metal chloride and europium chloride ${ }^{6)}$ In this paper, we demonstrated the ability to detect heavy metal ions $\left(\mathrm{Pb}^{2+}\right.$ or $\left.\mathrm{Zn}^{2+}\right)$ using the luminescence of polymerized cellulose films by assisting of rare earth ions $\left(\mathrm{Ce}^{3+}\right)$.

\section{Experimental}

The ceilulose film was prepared by the use of the 30 $\mathrm{ml}$ glass bottle container of which two parts was separated by a 100 mesh nylon cloth. The rare earth chloride $\left(\mathrm{CeCl}_{3}\right)$ solution $(10 \mathrm{mM}-100 \mathrm{mM})$ or the mixed solution of heavy metal chloride and rare earth chloride was put on the bottom of container. There was the viscous $\mathrm{Na}$ CMC solution $(4 \mathrm{mM})$ on a nylon cloth. Then the container was turned up side down and the solution contacted with each other through nylon cloth, followed by the formation of cellulose film containing of $\mathrm{Ce}^{3+}$ ions or $\mathrm{Ce}^{3+}$ ions and heavy metal ions. The nylon mesh cloth $(20 \mathrm{~mm} \phi \times 0.3 \mathrm{~mm})$ attaching cellulose thin film was re- moved from the container, washed and dried in a desiccator. The emission and excitation spectra were recorded by a Hitachi recording absolute spectrofluorophotometer (F-4500) at room temperature. The life times were measured with Nd-YAG laser $(266 \mathrm{~nm})$ having pulses of less than $5 \mathrm{~ns}$.

\section{Results and Discussion}

\section{1 The luminescence of $\mathrm{Ce}^{3+}$ in the cellulose film}

The luminescence of $\mathrm{Ce}^{3+}$ ions $(5 \mathrm{~d} \rightarrow 4 \mathrm{f}$ transition) was strong and simple. Also the photo-excitation energy of $\mathrm{Ce}^{3+}$ is larger than that of $\mathrm{Eu}^{3+}$. In this paper, europium ion changed to cerium ion as fluorescent probes. Photoluminescence spectra of $\mathrm{Ce}^{3+}$ for a $\mathrm{Ce}^{3+}$-cellulose film and some $\mathrm{Ce}^{3+}-\mathrm{M}^{\mathrm{n}+}$ (M:heavy metal) cellulose films under the excitation of $255 \mathrm{~nm}$ are shown in Fig. 1. The optimum excitation wavelength was same in every cases. The emission band centered at $350 \mathrm{~nm}$ which is well explained in terms of the dipole allowed $5 \mathrm{~d} \rightarrow 4 \mathrm{f}$ transition,

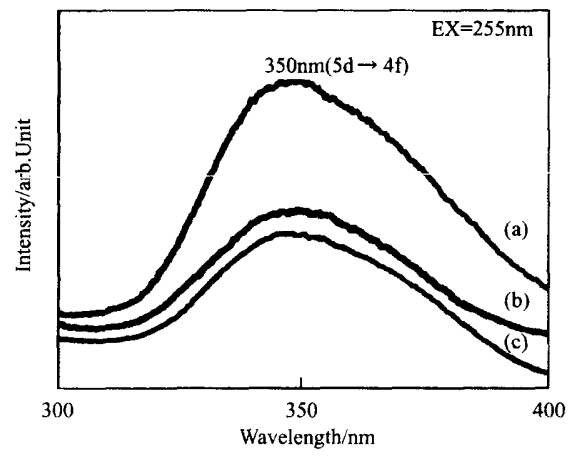

Fig. 1 The emission spectra of cellulose films containing $\mathrm{Ce}^{3+}$ ions. The film was prepared by the use of (a) $\mathrm{CeCl}_{3}$ (100 mM) solution, (b) the mixed solution of $\mathrm{CeCl}_{3}(100$ $\mathrm{mM}$ ) and $\mathrm{PbCl}_{2}(50 \mathrm{mM})$, (c) the mixed solution of $\mathrm{CeCl}_{3}$ $(100 \mathrm{mM})$ and $\mathrm{ZnCl}_{2}(50 \mathrm{mM})$. 


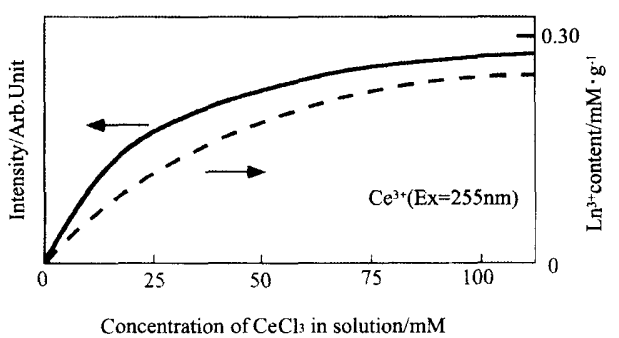

Fig. 2 The emission intensity and the content of $\mathrm{Ce}^{3+}$ ions in a polymerized Cellulose film vs the concentration of $\mathrm{CeCl}_{3}$ solution.

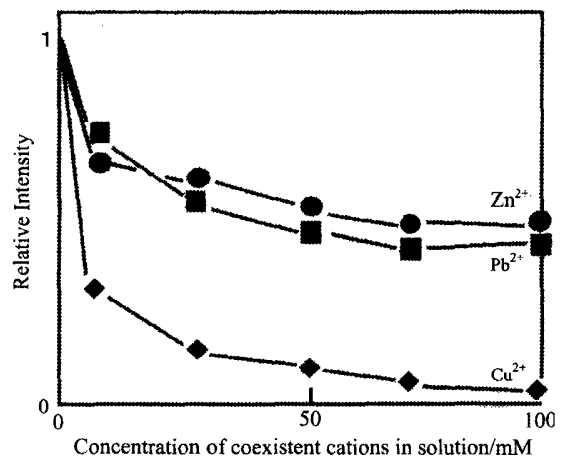

Fig. 3 Dependence of emission intensity of $\mathrm{Ce}^{3+}$ for $\mathrm{Ce}^{3+}$ $\mathrm{Zn}^{2+}, \mathrm{Ce}^{3+}-\mathrm{Pb}^{2+}$, and $\mathrm{Ce}^{3+}-\mathrm{Cu}^{2+}$ cellulose films on the content of cations. The cellulose films prepared using aqueous solution which changed the concentration of the heavy metal chloride by fixing the concent- ration of $\mathrm{CeCl}_{3}(100 \mathrm{mM})$.

are observed. The effect of varying $\mathrm{Ce}^{3+}$ ion concentration of cellulose films on the emission band is presented in Fig. 2. The abscissa indicates the concentration of $\mathrm{CeCl}_{3}$ when a cellulose film was prepared. At first, the intensity of emission band increased logarithmically with the concentration of $\mathrm{Ce}^{3+}$ ions in cellulose film up to $c a$. $0.25 \mathrm{mM} / \mathrm{g}$ (This point was corresponded to the concentration of solution for preparing a film), and then became almost constant. If the $\mathrm{Ce}^{3+}$-containing cellulose film was prepared together with $\mathrm{PbCl}_{2}, \mathrm{ZnCl}_{2}$ or $\mathrm{CuCl}_{2}$, the intensity of emission band of $\mathrm{Ce}^{3+}$ ions decreased as shown in Fig.1. Moreover, the intensity of the emission band decreased with the concentration of these heavy metal chlorides as shown in Fig. 3. The concentration of $\mathrm{Pb}^{2+}, \mathrm{Zn}^{2+}$, and $\mathrm{Cu}^{2+}$ in the cellulose film became almost constant over $50 \mathrm{mM}$ for the concentration of metal chloride solutions under experimental conditions. When the concentration of heavy metal ions and $\mathrm{Ce}^{3+}$ ions in a $\mathrm{Ce}^{3+}-\mathrm{I}^{2+}$ cellulose film was measured by X-ray fluorescence analysis, the cerium ion concentration was almost constant about $0.25 \mathrm{mM} / \mathrm{g}$ for every cases. On the other hand, there was the increase of the $\mathrm{M}^{2+}$ concentration in the cellulose film during the increase of $\mathrm{M}^{2+}$ ions of solution and then the $\mathrm{M}^{2+}$ ion concentration reaches almost constant value $(c a .0 .20 \mathrm{mM} / \mathrm{g})$ at $50 \mathrm{mM}$ solution, after which the concentration slightly increased up to $c a .0 .24$ $\mathrm{mM} / \mathrm{g}$ at $100 \mathrm{mM}$ solution. There was not large difference of $\mathrm{M}^{2+}$ concentration in a $\mathrm{Ce}^{3+}-\mathrm{M}^{2+}$ cellulose film between three heavy metal ions. The quenching effect was
Table 1 The relative intensity $\left(\mathrm{I}_{0} / \mathrm{I}\right)$ of $350 \mathrm{~nm}$ emission band and the relative decay time $\left(\tau_{0} / \tau\right)$ of $\mathrm{Ce}^{3+}$ ions for $\mathrm{Ce}^{3+}$ $\mathrm{M}^{\mathrm{n}}$ system.

\begin{tabular}{ccc}
\hline $\mathrm{M}^{\mathrm{n}}$ & $\mathrm{I}_{0} / \mathrm{I}^{\mathrm{a})}$ & $\tau_{0} / \tau^{\mathrm{b})}$ \\
\hline $\mathrm{Cu}^{2+}$ & 2.5 & 3.1 \\
$\mathrm{Co}^{2+}$ & 1.0 & 1.0 \\
$\mathrm{Mn}^{2+}$ & 1.0 & 1.0 \\
$\mathrm{Cr}^{3+}$ & 1.0 & 1.1 \\
$\mathrm{Fe}^{3+}$ & 5.0 & 2.3 \\
$\mathrm{Zn}^{2+}$ & 1.7 & 1.7 \\
$\mathrm{~Pb}^{2+}$ & 1.7 & 1.7 \\
\hline
\end{tabular}

a) These values were compared at $0.25 \mathrm{mM} / \mathrm{g}$ of $\mathrm{Ce}^{3+}$ and $0.2 \mathrm{mM}$ $/ \mathrm{g}$ of $\mathrm{M}^{\mathrm{n}+}$. b) $\tau_{0}$ was $3.4 \times 10 \mathrm{~ns}$. These values were compared at $0.25 \mathrm{mM} / \mathrm{g}$ of $\mathrm{Ce}^{3+}$ and $0.2 \mathrm{mM} / \mathrm{g}$ of $\mathrm{M}^{\mathrm{n}+}$, except for $\mathrm{Ce}^{3+}-\mathrm{Cr}^{3+}$ $(0.1 \mathrm{mM} / \mathrm{g})$ and $\mathrm{Ce}^{3+}-\mathrm{Fe}^{3+}(0.1 \mathrm{mM})$.

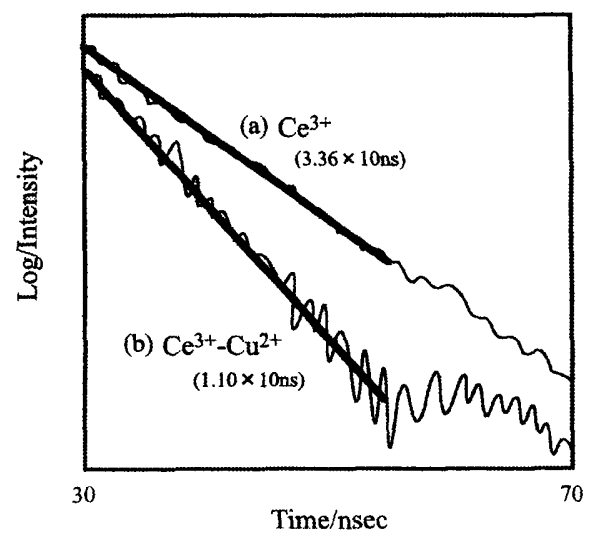

Fig. 4 Luminescence decay curves of an $\mathrm{Ce}^{3+}$ cellulose film and an $\mathrm{Ce}^{3+}-\mathrm{Cu}^{2+}$ cellulose film.

stronger in the lower concentration range of these heavy metal ions. The effect on the intensity of luminescence under coexistence of heavy metal ions were summarized in Table 1, together with the results of decay time as described later. When $\mathrm{Cu}^{2+}, \mathrm{Fe}^{3+}, \mathrm{Pb}^{2+}, \mathrm{Zn}^{2+}$ coexisted in the cellulose film, the luminescence was extremely decreased. In general, the luminescence of rare earth ion was strongly affected by $\mathrm{Fe}^{3+}$ ions as large absorption by $\mathrm{Fe}^{3+}$ ions exists from near $450 \mathrm{~nm}$. Therefore, in this paper the $\mathrm{Ce}^{3+}-\mathrm{Fe}^{3+}$ system was not discussed. It is well known that the intensity of luminescence for the cerium complexes is affected by the ligand. ${ }^{7)}$ On the other hand, heavy metals are known to be strong quenchers of luminescence. ${ }^{8)}$ The quenching of perdeuterated naphthalene by paramagnetic ions $\left(\mathrm{Co}^{2+}, \mathrm{Cr}^{3+}, \mathrm{Cu}^{2+}, \mathrm{Ni}^{2+}\right)$ was explained as the exchange-type interaction between the tripie state molecules and the paramagnetic ions. But, the decrease in the luminescence of $\mathrm{Ce}^{3+}-\mathrm{Co}^{2+}$ and $\mathrm{Ce}^{3+}$ $\mathrm{Cr}^{3+}$ was hardly observed, although $\mathrm{Co}^{2+}$ and $\mathrm{Cr}^{3+}$ is paramagnetic. Since $\mathrm{Zn}^{2+}$ or $\mathrm{Pb}^{2+}$ is not paramagnetic, it could not induce quenching by interaction from the viewpoint of Hoijtink's mechanism, ${ }^{9}$ but it may cause quenching by spin-orbit interaction due to its large atomic number. In our measurements with $\mathrm{Zn}^{2+}$ or $\mathrm{Pb}^{2+}$, the decrease of fluorescence intensity of $\mathrm{Ce}^{3+}$ was observed.

\section{2 The decay time of $\mathrm{Ce}^{3+}$ in the cellulose film}

The decay times and amplitudes of cerium lumines- 


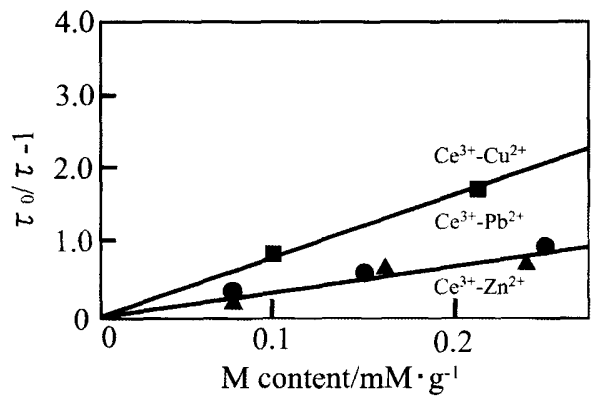

Fig. 5 Calibration graph for $\mathrm{Cu}^{2+}, \mathrm{Pb}^{2+}$ and $\mathrm{Zn}^{2+}$ in the linearized form of a Stern-Volmer plot.

cence for $\mathrm{a} \mathrm{Ce}^{3+}-\mathrm{Cu}^{2+}$ and $\mathrm{Ce}^{3+}$ system are shown in Fig. 4. In the presence of $\mathrm{Cu}^{2+}$ ions, the decay time $\tau$ (slope) was smaller than that of only $\mathrm{Ce}^{3+} \operatorname{system}\left(\tau_{0}\right)$. At the same time, the decrease of the amplitude was almost consistent with that of the luminescence intensity estimating by $\mathrm{I}_{0} / \mathrm{I}$. The same phenomena were observed in the $\mathrm{Ce}^{3+}-\mathrm{Pb}^{2+}$ and $\mathrm{Ce}^{3+}-\mathrm{Zn}^{2+}$ system. In comparison of $\mathrm{Ce}^{3+}-\mathrm{Pb}^{2+}$ with $\mathrm{Ce}^{3+}-\mathrm{Zn}^{2+}$ system, the difference was hardly appeared in the decay time. The changes in decay time and amplitude indicate the co-existence of static and dynamic quenching. The correlation between the concentration of these ions and $\tau_{0} / \tau$ are shown in Fig. 5. That is, the linear relationship in the range of lower concentration reflects the dynamic process, as predicted by the Stern-Volmer equation, ${ }^{9}$ ' whereas the decreasing of amplitude (or luminescence intensity) is mainly a result of static quenching. The relative decay times $\left(\tau_{0} / \tau\right)$ for other heavy metal ions are summarized in Table 1 . According to the Stern-Volmer equation, the extent of quenching is proportional to the decay time of the cerium luminescence. The absorption spectrum of $\mathrm{Fe}^{3+}$, which was a dynamic quencher, has a higher overlap with the emission spectrum of the cerium ion. On the other hand, it was expected that in the $\mathrm{Ce}^{3+}-\mathrm{Pb}^{2+}$ and $\mathrm{Ce}^{3+}-\mathrm{Zn}^{2+}$ system the dynamic quenching and the decrease of the decay time were not observed, because none of the completely colorless ions showed dynamic quenching. In the $\mathrm{Eu}^{3+}-\mathrm{Pb}^{2+}$ and $\mathrm{Eu}^{3+}-\mathrm{Zn}^{2+}$ system, quenching and the decrease of decay time were not clearly observed as reported in elsewhere. ${ }^{6)}$ Although the mechanism of quenching for $\mathrm{Ce}^{3+}-\mathrm{M}^{2+}$ system could not be clarified, the clear quenching of $\mathrm{Ce}^{3+}-\mathrm{Pb}^{2+}$ and $\mathrm{Ce}^{3+}-\mathrm{Zn}^{2+}$ system may be due to the larger photo-excitation energy; the photo-excitation energy of $\mathrm{Ce}^{3+}-\mathrm{M}^{2+}$ system $(\mathrm{Ex}=255 \mathrm{~nm})$ was larger than that of $\mathrm{Eu}^{3+}-\mathrm{M}^{2+}$ system $(\mathrm{Ex}=395 \mathrm{~nm})$. In $\mathrm{Pb}^{2+}$ or $\mathrm{Zn}^{2+}$ ions which the $\mathrm{d}$ oribital has satisfied, one of $3 \mathrm{~d}$ or $4 \mathrm{~d}$ electron would be excited in $4 \mathrm{~s}$ or $5 \mathrm{~s}$ orbital when $\mathrm{Pb}^{2+}$ or $\mathrm{Zn}^{2+}$ ions was excited by $255 \mathrm{~nm}$ light. In the $\mathrm{Ce}^{3+}-\mathrm{Pb}^{2+}$ and $\mathrm{Ce}^{3+}-\mathrm{Zn}^{2+}$ system the early energy transfer process going through excitation state of $\mathrm{Pb}^{2+}$ or $\mathrm{Zn}^{2+}$ ions would predominantly occur.

The operation of the method presented is simple. These results suggest that the present method has the ability of the detection of transition metal ions in environmental waters, including river water and industrial wastewater.

\section{Conclusions}

The luminescence and the decay time of $\mathrm{Ce}^{3+}$ ions in cellulose polymer film which was prepared by $\mathrm{Na}-\mathrm{CMC}$ solution and $\mathrm{CeCl}_{3}$ solution or the mixed solution of $\mathrm{CeCl}_{3}$ and a heavy metal chloride, was studied. The quenching of cerium luminescence depended on the kind of the heavy metal ion. In the $\mathrm{Ce}^{3+}-\mathrm{Cu}^{2+}, \mathrm{Ce}^{3+}-\mathrm{Pb}^{2+}$ and $\mathrm{Ce}^{3+}-\mathrm{Zn}^{2+}$ system, the relative decay time linearly varied with the concentration of these heavy metal ions in the range of lower concentrations. This method based on quenching of cerium luminescence may be useful for the determination of the heavy metal.

\section{References}

1) E. P. Diamandis and T. K. Christopoulos, Anal. Chem., 62, 1149A (1990).

2) T. Yamada, S. Shinoda, J. Uenishi, and H. Tsukube, Tetrahedron Lett., 42, 9031 (2001).

3) M. P. Baily, B. F. Rocks, and C. Riley, Analyst, 109, 1449 (1984).

4) Y. Ueba, E. Banks, and Y. Okamoto, J. Appl. Poly. Sci., 25, $2007(1980)$.

5) A. L. Jenkins, O. M. Uy, and G. M. Murray, Anal. Chem., 71, 373 (1999).

6) T. Arakawa and M. Akamine, 9th International Meeting on Chemical Sensors, Abstr., p.184 (2002).

7) C. O. Hill and S. H. Lin, J. Chem. Phys., 53, 608 (1970).

8) G. J. Hoijtink, Mol. Phys., 3, 67 (1960).

9) O. S. Wolfbeis, Molecular Luminescence Spectroscopy (Ed. Schulman), Wiley, New York, 202 (1988). 